\title{
Comment on the report "Operational Earthquake Forecasting" by the International Commission on Earthquake Forecasting for Civil Protection
}

\author{
Stuart Crampin ${ }^{1,2, \star}$ \\ ${ }^{1}$ British Geological Survey, Edinburgh, United Kingdom \\ 2 also at University of Edinburgh, School of GeoSciences, Edinburgh, United Kingdom
}

\section{Article history}

Received December 6, 2011; accepted February 27, 2012.

Subject classification:

Comment, Critical-systems, Earthquake forecasting, ICEF Report, Operational earthquake forecasting, Shear-wave splitting, Stress-forecasting.

Ein jedes Problem durchläuft bis zu seiner Anerkennung drei Stufen: In der ersten wird es lächerlich gemacht, in der zweiten bekämpft, in der dritten gilt es als selbstverständlich.

(All truth passes through three stages. First, it is ridiculed. Second, it is violently opposed. Third, it is accepted as self-evident.)

A. Schopenhauer (1788-1860)

\begin{abstract}
The recently published report Operational Earthquake Forecasting: State of Knowledge and Guidelines for Utilization by the International Commission on Earthquake Forecasting for Civil Protection (ICEF) presupposes that there is no method for the short-term prediction of large earthquakes that has been demonstrated to be both reliable and skillful. This is no longer correct. Earthquakes can be deterministically stress-forecast by using shear-wave splitting to monitor stress-accumulation in the rock mass surrounding the earthquake source. This new understanding of fluid-rock deformation means that the recommendations of the ICEF Report are no longer appropriate. This comment reviews this new understanding and suggests that the way forward for operational earthquake forecasting in Italy is to install one or more controlled-source three-borehole Stress-Monitoring Sites and use shear-wave splitting to monitor stress-accumulation and stress-forecast all damaging $(M \geq 5)$ earthquakes in Italy.
\end{abstract}

\section{Introduction}

The report Operational Earthquake Forecasting: State of Knowledge and Guidelines for Utilization was published by the International Commission on Earthquake Forecasting for Civil Protection (ICEF) [Jordan et al. 2011]. ICEF was convened by the Department of Civil Protection, Rome, Italy, in order to provide recommendations and guidelines for "operational earthquake forecasting" for Italy following the devastating April 6, 2009, $M=6.3$, L'Aquila Earthquake in central Italy. "The goal of operational earthquake forecasting is to provide communities with information about seismic hazards that can be used to make decisions in advance of potentially destructive earthquakes" where "One of the outstanding challenges in the operational use of probabilistic forecasts is in translating them into decisionmaking in a low-probability environment" [Executive Summary, ICEF Report, Jordan et al. 2009]. Experts from nine countries surveyed earthquake forecasting procedures in six seismically active countries and, citing nearly 500 documents, produced a survey of earthquake forecasting in a closely reasoned 77-page report. The report made 13 recommendations [Jordan et al. 2011], listed in Table 1. The Commission intended that this comprehensive survey will be "useful not only in Italy, but also in other seismically active regions where operational earthquake forecasting may be warranted", where as noted above, the basis for operational earthquake forecasting is "decision-making in a lowprobability environment" [Jordan et al. 2011]. The low-probability environment is specified because the report concludes inter alia that: "The Commission has identified no method for the short-term prediction of large earthquakes that has been demonstrated to be both reliable and skillful".

One might have hoped that such a comprehensive seemingly well-founded report would be definitive for some years to come. Unfortunately the Commission omits a new understanding of fluid-rock deformation, a New Geophysics [Crampin 2006, Crampin and Peacock 2008], that demonstrates that seismic shear-wave splitting monitors stress-accumulation in almost all in situ rocks before release by earthquakes. This means that the times, magnitudes, and in some cases faultbreaks of impending large earthquakes can be stress-forecast in a high-probability environment [Crampin 2011, Crampin et al. 1999, Crampin et al. 2008], where the term stress forecasting is used rather than prediction to emphasize the different formalism. The ability to stress-forecast earthquakes in a high-probability rather than a low-probability environment modifies the recommendations of the ICEF Report. 


\begin{tabular}{ll}
\hline Headings & ICEF Recommendations \\
\hline $\begin{array}{l}\text { Need for probabilistic } \\
\text { earthquake forecasting: }\end{array}$ & $\begin{array}{l}\text { A: DPC } \\
\text { infrastructure and expertise needed to utilize probabilistic information for operational purposes. }\end{array}$ \\
\hline Earthquake monitoring: & $\begin{array}{l}\text { B1: DPC should coordinate across Italian agencies to improve the flow of data, in particular seismic and geodetic monitoring } \\
\text { data, into operational earthquake forecasting. } \\
\text { B2: Particular emphasis should be placed on real-time processing of seismic data and the timely production of high-quality } \\
\text { earthquake catalogs and strain-rate maps. } \\
\text { B3: Opportunities for establishing well-instrumented natural laboratories for studying earthquake generation processes } \\
\text { should be supported. }\end{array}$
\end{tabular}

Research on earthquake predictability:
C: A basic research program focused on the scientific understanding of earthquakes and earthquake predictability should be part of a balanced national program to develop operational forecasting.

Development of long-term D: DPC should continue its directed research program on development of time-independent and time-dependent forecasting models: forecasting models with the objective of improving long-term seismic hazard maps that are operationally oriented.

Development of short-term E1: DPC should emphasize the deployment of an operational capability for forecasting aftershocks.

forecasting models: $\quad$ E2: DPC should support development of earthquake forecasting methods based on seismicity changes to quantify shortterm probability variations.

Validation of earthquake forecasting methods:
F1: Forecasting methods intended for operational use should be scientifically tested against the available data for reliability and skill, both retrospectively and prospectively. All operational models should be under continuous prospective testing. F2: The international infrastructure being developed to test earthquake forecasting methods prospectively should be uses as a tool for validating the forecasting models for Italy.
Utilization of earthquake forecasts:
G1: An independent panel of experts should be created to evaluate forecasting methods and interpret their output. This panel should report directly to the head of DPC.

G2: Quantitative and transparent protocol should be established for decision-making that include mitigation actions with different impacts that would be implemented if certain thresholds in earthquake probability are exceeded.
Public communication of earthquake information:
H: DPC, in accordance with social-science principles on effective public communication and in concert with partner organizations, should continuously inform the public about the seismic situation in Italy based on probabilistic forecasting.

Table 1. Recommendations of the ICEF Report [Jordan et al. 2011]. DPC = Dipartimento della Protezione Civile Italiana.

\section{The New Geophysics: the new understanding of fluid- rock deformation}

Worldwide observations of stress-aligned shear-wave splitting (SWS) above swarms of small earthquakes, and in seismic surveys by the exploration industry, record $\sim 1.5 \%$ to $\sim 4.5 \%$ shear-wave velocity anisotropy (SWVA) in all ostensiblyintact unfractured rock: crystalline, sedimentary, igneous, metamorphic, high-porosity, low-porosity, consolidated, unconsolidated [Crampin and Peacock 2008]. Figure 1 is a schematic illustration of SWS. Anisotropic symmetries show that the parallel polarizations of the leading split shear-wave can only be caused by distributions of stress-aligned fluidsaturated parallel vertical microcracks [Crampin and Peacock 2008]. Since crack density for parallel cracks is one hundredth of the percentage SWVA, the range crack densities $(C D=\sim 0.015$ to $\sim 0.45)$ is illustrated schematically in the left-hand side of the microcrack images in Figure 2 [Crampin 1994, Crampin and Zatsepin 1997].

Figure 2 is definitive. It demonstrates that almost all in situ rocks, except perhaps specifically heavily-fractured beds, are pervaded by stress-aligned fluid-saturated microcracks verging on fracture-criticality when cracks are

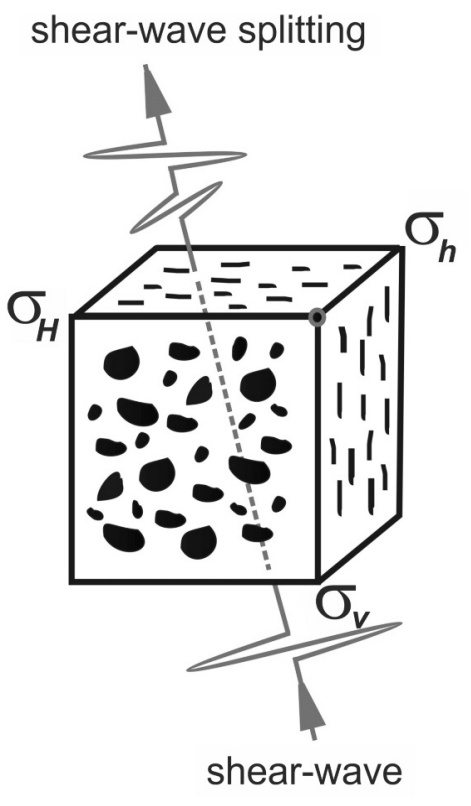

Figure 1. Schematic illustration of shear-wave splitting on propagating through the fluid-saturated stress-aligned microcracks pervasive in most rocks in the Earth's crust [after Crampin 1994]. 


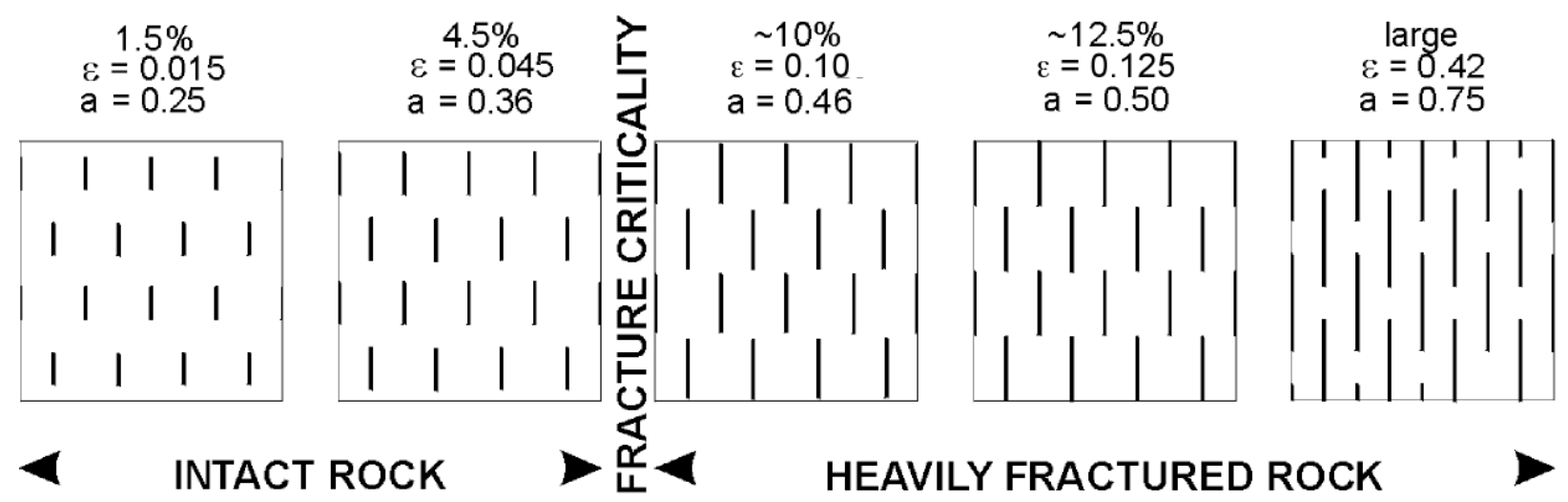

Figure 2. Schematic dimensionless illustrations of the observed percentages of shear-wave velocity-anisotropy interpreted as uniform distributions of equal-sized parallel penny-shaped cracks with the same percentage anisotropy, where $\varepsilon$ is crack density, and $a$ is crack radius per unit cube. Fracture criticality is at the percolation threshold of $\varepsilon=0.055$ for parallel cracks, where cracks are so closely spaced they fracture if there is any disturbance. [After Crampin 1994].

so closely-spaced that they fail (in fracturing and earthquakes) whenever there is any disturbance. Fracturecriticality is identified with the percolation threshold of $C D=\sim 0.55$ (for stress-aligned cracks) where cracks are so numerous, that through-going percolation paths exist [Crampin and Zatsepin 1997]. Such phenomena verging on failure are critical-systems leading to deterministic chaos, and are a New Physics [Davies 1989] (hence a New Geophysics), which imposes a range of fundamental new properties on conventional sub-critical geophysics [Crampin 2006]. Evidence supporting the New Geophysics, inexplicable in terms of conventional subcritical geophysics is listed in Table 3.

The properties implied by Figure 2 are listed in Table 2 . They include: self-similarity; monitorability; calculability; predictability; in principle, controllability; universality; and extreme (butterfly wings) sensitivity. This range of new properties is fundamentally different from conventional sub-critical geophysics and requires a paradigm shift in understanding before they can be accepted. As a result, New Geophysics tends to be controversial as the properties

\section{New properties ${ }^{\star}$}

Effects

P1) Self-similarity: logarithmic plots of related quantities are linear [Gutenberg and Richter 1956, Gao and Crampin 2004, Wu et al. 2006].

Confirms the link between earthquakes and critical-systems.

P2) Monitorability: behavior of in situ microcracks can be monitored by SWS [Crampin 1994, 1999].

Allows SWS to monitor stress-accumulation and stress-relaxation in the in situ rock mass.

P3) Calculability: evolution of microcrack geometry can be calculated by anisotropic poro-elasticity (APE) [Crampin and Zatsepin 1997, Crampin 1999, Angerer et al. 2002].

Allows the effects of changes in stress to be robustly calculated by comparatively simple expressions.

P4) Predictability: if the changes in conditions are known, behavior can Allows the effects of changes in conditions to be robustly calculated and be predicted by APE [Angerer et al. 2002]. predicted if the changes are known.

P5) Controllability: if behavior can be calculated by P3), changes predicted by $\mathrm{P} 4$, the behavior can be controlled (by modifying injection pressures, say) by feedback.
Suggests that in principle the behavior of some production processes in hydrocarbon recovery, say, can be calculated and controlled.
P6) Universality: critical-systems pervade all available space [Crampin and Chastin 2003, Crampin and Gao 2012a].
Allows changes to be identified at great distances: changes in low-level stress before the 2004, M 9.2, Sumatra-Andaman Earthquake were recognized in Iceland at $\sim 10,500 \mathrm{~km}$, the width of the Eurasian plate, from Indonesia.
P7) Sensitivity: there is extreme (butterfly-effect) sensitivity [Lorenz 1972] to miniscule differences in starting position [Crampin et al. 2003, Crampin and Gao 2012a].
Sensitivity is one of the defining properties of the New Geophysics that allows stress-accumulation to be monitored at great distance from the impending source, as in Sumatra-Andaman Earthquake in P5.

Table 2. New properties imposed on conventional sub-critical geophysics by the New Geophysics of the compliant fluid-saturated stress-aligned microcracked crust. ${ }^{\star}$ All these properties have been observed in situ whenever appropriate recordings are available. There are no known exceptions. 
Evidence inexplicable in terms of conventional sub-critical geophysics $\uparrow$

E2 There is a minimum shear-wave velocity anisotropy (SWVA) of $\sim 1.5 \%$ in most in situ rocks;

E3 There is a maximum SWVA of $\sim 4.5 \%$ in ostensibly unfractured rock;

E4 The fracture-criticality limit of SWVA is $\sim 5.5 \%$ in in situ rocks is independent of rock-type, geology, tectonics, and porosity, where SWVA of $\sim 5.5 \%$ is the percolation threshold for parallel cracks;

E5 High pore-fluid pressures induce $90^{\circ}$-flips in polarizations of the faster split shear-waves;

E6 Explains the large (" $\pm 80 \% ")$ scatter in observations of shear-wave time-delays above small earthquakes;

E7 Effect of CO2-injections on seismic reflection survey in carbonate reservoir modeled by APE;

E8 Stress-accumulation observed before earthquakes;

E9 Time, magnitude, and impending fault-break successfully stress-forecast in real time;

E10 Stress-relaxation (crack-coalescence) observed before earthquakes;

E11 Stress-accumulation observed before volcanic eruptions;

E12 Extreme sensitivity: stress-variations before the 2004 M 9.2 Sumatra-Andaman EQ observed in Iceland at the width of the Eurasian Plate $(\sim 10,500 \mathrm{~km})$ from Indonesia;

E13 Explains how a stressed rock differs from an unstressed rock;

E14 Explains how the enormous stress-energy before a large earthquake accumulates without inducing smaller earthquakes;

E15 Explains why initial stress drop at an earthquake is small (typically 2 to $4 \mathrm{MPa}$ ) and independent of earthquake magnitudes varying by over 10 orders of magnitude;

E16 Explains how irregular fault-planes slip when constrained by enormous lithostatic stress;

E17 Explains why we cannot deterministically predict but can stress-forecast the time, magnitude, and fault-break of impending earthquakes;

E18 Explains why the Gutenberg and Richter [1956] relationship between logarithms of cumulative frequencies of earthquakes and earthquake magnitudes is linear;

E19 Explains why subduction-zone earthquakes are preceded and followed by episodic tremor and slip;

E20 Explains why, despite huge investments, on average less than $40 \%$ of in-place oil is recovered;

†without specifying innumerable special cases.
[1] Crampin [1994];
[2] Crampin and Peacock [2008];
[4] Angerer et al. [2002];
[5] Crampin et al. [2002];
[7] Volti and Crampin [2003b];
[8] Crampin et al. [1999];
[10] Crampin et al. [2008];
[11] Gao and Crampin [2004];
[13] Crampin et al. [2012];
[14] Crampin and Gao [2012b];
[3] Crampin and Zatsepin [1997];
[6] Crampin et al. [2004a];
[9] Crampin et al. [2004b];
[12] Crampin and Gao [2012a];
[15] Crampin [2006].

Table 3. Evidence supporting APE deformation and the New Geophysics of a compliant calculable stress-sensitive microcracked rock mass.

are not easily accepted from experience based on conventional sub-critical geophysics. Witness the reply of Jordan and Jones [2011] to earlier comments by Crampin [2011] on a preliminary outline of the ICEF Report [Jordan and Jones 2010]. Perhaps the "violent opposition" of Schopenhauer' stage 2 is appropriate.

\section{Monitoring fluid-rock deformation and stress- forecasting earthquakes}

The effects of stress on in situ rock can be monitored by observations of SWS imaging microcrack geometry [Crampin and Peacock 2008]. Interpretation of observations of SWS shows that increases of stress in the Earth's crust typically originate from magma generation and the subduction and interactions at tectonic plate margins. Initially, such increasing stress is general and widespread and the faults where the stress will be released by earthquakes are not initially identified. The accumulating stress modifies crack aspect-ratios throughout the stressed rock mass until the microcrack geometry begins to approach levels of fracture criticality. Only then does the stress-field recognize the weakness of the impending fault-plane, and there is stress-relaxation as microcracks begin to coalesce onto the impending fault break [Gao and Crampin 2004, Wu et al. 2006, Crampin and Peacock 2008]. The Earth is highly heterogeneous and stress accumulates irregularly. If stress increases over a small rock volume, the increase will be rapid but the eventual earthquake will be small. If stress increases 
over a larger volume, the increase will be slower but the eventual earthquake will be larger. As a result, duration of the changes and the magnitudes are self-similar (P1, Table 2), so that monitoring these stress changes in the surrounding rock mass allows the time, magnitude, and in some cases fault break, of the impending earthquake to be stress-forecast.

Characteristic patterns of stress-accumulation increases and stress-relaxation (crack-coalescent) decreases have been recognized retrospectively before 15 earthquakes ranging from a $M=1.7$ swarm event in Iceland [Crampin et al. 2008] to the $M=9.2,2004$, Sumatra-Andaman Earthquake (where changes in SWS were recognized in Iceland at the width of the Eurasian Plate $(\sim 10,500 \mathrm{~km})$ from Indonesia, [Crampin and Gao 2012a]). In one case when seismic data from Iceland was being monitored online, the time, magnitude, and faultbreak of a $M=5$ earthquake in Iceland was successfully stress-forecast three days before it occurred [Crampin et al. 1999, 2008]. This $M=5$ earthquake is claimed as the first scientifically forecast earthquake [Crampin et al. 1999, 2008].

Such stress-forecasting can be repeated whenever and wherever SWS can be routinely monitored. Unfortunately, swarms of small earthquakes are far too scarce and irregular for routine observations of SWS, except in Iceland where two transform faults of the Mid-Atlantic Ridge uniquely run on shore, and provide the persistent low-level seismicity necessary for reliable routine stress-forecasting [Volti and Crampin 2003a, 2003b].

\section{Potential for routine stress-forecasting at three- borehole Stress-Monitoring Sites}

Monitoring SWS for stress-induced changes in in situ rocks needs to be below the near-surface to avoid stress-release and weathering anomalies, and below the depth $(\sim 1000 \mathrm{~m}$, say) where the vertical stress, $\sigma_{V}$, becomes greater than the minimum horizontal stress, $\sigma_{h}$. This means that the principal axes of stress have the same orientations as $\sigma_{V}$ increases with depth, so that direct interpretation of SWS time-delays can be made from the surface observations [Crampin 1999].

Reliable routine stress-forecasting requires cross-hole seismology at a three $(1000 \mathrm{~m}$ to $1500 \mathrm{~m}$-deep) borehole Stress-Monitoring Site (SMS) using a Downhole Orbital Vibrator (DOV) to transmit shear-waves along specific stressoriented directions and angles of incidence [Crampin 2001]. The prototype SMS between existing boreholes adjacent to the Húsavík-Flatey transform fault of the Mid-Atlantic Ridge, where it runs onshore in northern Iceland, did not have optimum source-to-receiver borehole geometry, yet demonstrated the anticipated butterfly-effect sensitivity [Crampin et al. 2003]. Horizontal propagation over $315 \mathrm{~m}$ at $500 \mathrm{~m}$-depth recorded seven anomalies in $P$-wave and SWS travel-times, SWVA, NS and EW GPS, and water-depth changes at a well on Flatey immediately about the HúsavíkFlatey transform fault. The anomalies coincided and appear to have been induced by a swarm of small earthquakes with equivalent seismic energy to a $M=3.5$ earthquake at $70 \mathrm{~km}$ distance on the neighboring Grímsey-Lineament transform fault and hundreds of times the conventional earthquake source diameter.

Such exceptional (butterfly-effect) sensitivity suggests that a single three-well SMS would detect stress changes before a $M=5$ earthquake up to $1000 \mathrm{~km}$ from a SMS [Crampin and Gao 2012a]. Thus a single SMS installed in central Italy has the potential for stress-forecasting the time and magnitude of all damaging $(M \geq 5)$ earthquakes on the mainland of Italy. In our current understanding of the phenomena, stress-forecasting the location of the fault break would require interpretation of local precursory effects. However, knowing a large earthquake is approaching allows other phenomena, which might otherwise be ignored, to be interpreted correctly. This happened with the successful stress-forecast of the $M=5$ earthquake in Iceland, where continuing seismicity following a $M=5.1$ earthquake six-months earlier correctly suggested the impending fault break in a successfully stress-forecast earthquake [Crampin et al. 1999, 2008].

\section{Stress-monitoring volcanic eruptions}

Stress accumulation changes in SWS have also been observed before volcanic eruptions [Miller and Savage 2001, Volti and Crampin 2003b, Bianco et al. 2006], which Gerst and Savage [2004] have suggested could be used as an eruption forecasting tool. This is not unexpected as vents need to fracture before magma can be ejected and require similar stress-accumulation as before earthquakes. There have been few examples of measurements of SWS before eruptions and these have not confirmed that stress-relaxation (crack-coalescence) decreases occur before eruptions.

The observations of Volti and Crampin [2003b] are believed to monitor two-year spreading cycle of the MidAtlantic Ridge. In 2006, the Gjàlp volcano had a fissure eruption beneath the Vatnajökull Ice Sheet which was preceded by a five-month stress-accumulation increase. In 2006, at a workshop in Iceland, I reported an increase in SWS time-delays one month before the eruption [Stefánsson 2011], which in effect stress-forecast the eruption. However, at that time our understanding of SWS was just evolving and we did not make an association with an impending eruption. Following the eruption the normalized SWS time-delays at all stations in Iceland displayed a $2 \mathrm{~ms} / \mathrm{km} /$ year (stressrelaxation) decrease in time-delays that lasted two years.

Installation of SMSs in Italy would also provide the opportunity to stress-forecast eruptions of Vesuvius and Etna.

\section{Conclusions}

The 13 recommendations of the ICEF Report in Table 1 are based on the mistaken assumption that "reliable and skillful deterministic earthquake prediction is not yet 
possible" [Jordan et al. 2011]. In this comment I have outlined how observations of seismic shear-wave splitting monitored at a three-borehole Stress-Monitoring Site (SMS) in central Italy could monitor stress-accumulation and stress-relaxation (crack-coalescence) before all damaging $(M \geq 5)$ earthquakes within 1000km of the SMS [Crampin and Gao 2012a]. This means that installation of one expensive SMS (preferably two throughout the length of Italy) would stress-forecast the time, magnitude, and in some circumstances the fault-break of all potentially damaging earthquakes on the mainland of Italy. Monitoring of earthquakes and eruptions of Etna on Sicily would probably require a further SMS.

Note that the IASPEI Scientific Assembly, Melbourne, Australia endorses and recommends the final ICEF Report in Resolution 4, IASPEI [2011]. Consequently, these demonstrations of the unreliability of the ICEF Report suggest that IASPEI Resolution 4 needs amending.

Acknowledgments. This work is published with the permission of the Executive Director of the British Geological Survey (NERC).

\section{References}

-Angerer, E., S. Crampin, S., X.-Y. Li and T.L. Davis (2002). Processing, modelling, and predicting time-lapse effects of overpressured fluid-injection in a fractured reservoir, Geophys. J. Int., 149, 267-280.

Bianco, F., L. Scarfi, E. Del Pezzo and D. Patanè (2006). Shear wave splitting changes associated with the 2001 volcanic eruption on Mt Etna, Geophys. J. Int., 167, 959-967.

'Crampin, S. (1994). The fracture criticality of crustal rocks, Geophys. J. Int., 118, 428-438.

'Crampin, S., and S.V. Zatsepin (1997); Modelling the compliance of crustal rock: II - response to temporal changes before earthquakes, Geophys. J. Int., 129, 495-506.

'Crampin, S. (1999). Calculable fluid-rock interactions, J. Geol. Soc., 156, 501-514.

•Crampin, S., T. Volti and R. Stefánsson (1999). A successfully stress-forecast earthquake, Geophys. J. Int., 138, F1-F5.

-Crampin, S. (2001). Developing stress-monitoring sites using cross-hole seismology to stress-forecast the times and magnitudes of future earthquakes, Tectonophysics, 338, 233-245. Note updated geometry in online version.

'Crampin, S., T. Volti, S. Chastin, A. Gudmundsson and R. Stefánsson (2002). Indication of high pore-fluid pressures in a seismically-active fault zone, Geophys. J. Int., 151, F1F5.

-Crampin, S., and S. Chastin (2003). A review of shear-wave splitting in the crack-critical crust, Geophys. J. Int., 155, 221-240.

'Crampin, S., S. Chastin and Y. Gao (2003). Shear-wave splitting in a critical crust: III - preliminary report of multivariable measurements in active tectonics, J. Appl. Geophys., 54, 265-277.

'Crampin, S., S. Peacock, Y. Gao and S. Chastin (2004a). The scatter of time-delays in shear-wave splitting above small earthquakes, Geophys. J. Int., 156, 39-44.

'Crampin, S., T. Volti and R. Stefánsson (2004b). Response to "A statistical evaluation of a 'stress-forecast' earthquake" by T. Seher and I. G. Main, Geophys. J. Int., 157, 194-199. -Crampin, S. (2006). The New Geophysics: a new understanding of fluid-rock deformation, In: Eurock 2006: Multiphysics coupling and long term behaviour in rock mechanics, A. Van Cotthem, R. Charlier, J.-F. Thimus, and J.-P. Tshibangu, eds., Taylor and Francis, London, 539-544.

'Crampin, S., and S. Peacock (2008). A review of the current understanding of shear-wave splitting and common fallacies in interpretation, Wave Motion, 45, 675-722.

'Crampin, S., Y. Gao and S. Peacock (2008). Stress-forecasting (not predicting) earthquakes: A paradigm shift?, Geology, $36,427-430$.

'Crampin, S. (2011). A second opinion on "Operational earthquake forecasting: some thoughts on why and how", by Thomas H. Jordan and Lucile M. Jones, Seism. Res. Lett., 82, pp. 227-230.

Crampin, S., and Y. Gao (2012a). The New Geophysics, Terra Nova, submitted.

'Crampin, S., and Y. Gao (2012b). Plate-wide deformation before the Sumatra-Andaman Earthquake, J. Asian Earth Sci., 46, 61-69; doi:10.1016/j.jseaes.2011.1015.

Crampin, S., and Y. Gao (2012c). Mechanisms of low-frequency earthquakes and episodic tremor and slip, Terra Nova, in preparation.

Crampin, S., Y. Gao and A. Santis (2012). A few earthquake conundra resolved, Terra Nova, submitted.

Davies, P. (1989). The New Physics: a synthesis, In: The New Physics, P. Davies (ed.), Cambridge Univ. Press., pp. 1-6.

-Gao, Y. and S. Crampin (2004). Observations of stress relaxation before earthquakes, Geophys. J. Int., 157, 578-582.

Gerst, A., and M. Savage (2004). Seismic anisotropy beneath Ruapehu volcano: A possible eruption forecasting tool, Science, 306, 1543-1547.

Gutenberg, B., and C.F. Richter (1956). Magnitude and energy of earthquakes, Annali di Geofisica, 9 (1), 1-15; republished in Annals of Geophysics, 53 (1), 2010, doi: 10.4401 /ag-4588.

IASPEI (2011) www.iaspei.org/resolutions/resolutions_2011 _melbourne.pdf.

Jordan, T.H., Y.-T. Chen, P. Gasparini, R. Madariaga, I. Main, W. Marzocchi, G. Papdopoulos, G. Sobelev, K. Yamaoka and J. Zschau (2009). Operational earthquake forecasting: State of knowledge and guidelines for implementation. Findings and recommendations of the International Commission on Earthquake Forecasting for Civil Protection, released by the Dipartimento della Protezione Civile, Rome, Italy, 2 October, 2009.

Jordan, T.H., and L.M. Jones (2010). Operational earthquake forecasting: some thoughts on why and how, Seism. Res. 
Lett., 81, 571-574.

Jordan, T.H., and L.M. Jones (2011). Reply to "A second opinion on 'Operational earthquake forecasting: some thoughts on why and how', by Thomas H. Jordan and Lucile M. Jones', by Stuart Crampin", Seism. Res. Lett., 82, 231-232.

Jordan, T.H., Y.-T. Chen, P. Gasparini, R. Madariaga, I. Main, W. Marzocchi, G. Papadopoulos, G. Sobelev, K. Yamaoka and J. Zschau (2011). Operational Earthquake Forecasting: State of Knowledge and Guidelines for Utilization, Annals of Geophysics, 54 (4), 315-391; doi: 10.4401/ag5350 .

Lorenz, E.N. (1972). Predictability: does the flap of a butterfly's wings in Brazil set off a tornado in Texas?, Ann. Mtg. Am. Assoc. Adv. Sci., Washington D.C.

Miller, V., and M. Savage (2001). Changes in seismic anisotropy after volcanic eruptions: evidence from Mount Ruapehu, Science, 293, 2231-2235.

Stefánsson, R. (2011). Advances in earthquake prediction, Springer-Praxis Books, New York, p 91.

-Volti, T., and S. Crampin (2003a). A four-year study of shearwave splitting in Iceland: 1. Background and preliminary analysis, In: New insights into structural interpretation and modelling, D.A. Nieuwland, ed., Geol. Soc. Lond., Spec. Publ., 212, 117-133.

-Volti, T., and S. Crampin, (2003b). A four-year study of shear-wave splitting in Iceland: 2. Temporal changes before earthquakes and volcanic eruptions, In: New insights into structural interpretation and modelling, D.A. Nieuwland, ed., Geol. Soc. Lond., Spec. Publ., 212, 135-149.

'Wu, J., S. Crampin, Y. Gao, P. Hao, T. Volti and Y.-T. Chen (2006). Smaller source earthquakes and improved measuring techniques allow the largest earthquakes in Iceland to be stress-forecast (with hindsight), Geophys. J. Int., 166, 1293-1298.

- Papers available at www.geos.ed.ac.uk/homes/scrampin/ opinion.

\footnotetext{
${ }^{\star}$ Corresponding author: Stuart Crampin, British Geological Survey, Edinburgh, United Kingdom; email: scrampin@ed.ac.uk; www.geos.ed.ac.uk/homes/scrampin/ opinion. 